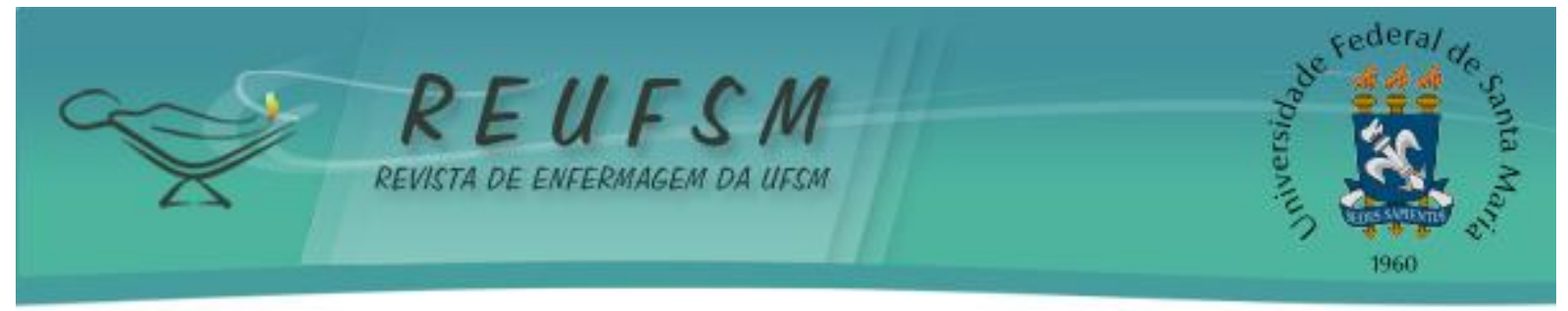

RELATO DE EXPERIÊNCIA

\title{
O ENFERMEIRO NO PROCESSO PARIR/NASCER: ESTRATÉGIA DE CUIDADO E HUMANIZAÇÃO DO PARTO
}

\author{
THE NURSE IN THE BIRTH PROCESS: A STRATEGY OF CARE AND HUMANIZATION \\ OF CHILD DELIVERY
}

\section{EL ENFERMERO EN EL PROCESO DE PARIR/NACER: ESTRATEGIA DE ATENCIÓN Y HUMANIZACIÓN DEL PARTO}

\author{
Elza Aparecida Gomes Velasque ${ }^{1}$ \\ Vania Marta Pradebon ${ }^{2}$ \\ Fernanda Berhegaray Cabral ${ }^{3}$
}

RESUMO: 0 artigo relata vivências da prática assistencial, desenvolvida em uma Estratégia Saúde da Família e na maternidade de um hospital, como Trabalho de Conclusão de Curso, junto às mulheres-gestantes-parturientes. As ações compreenderam: práticas educativas no âmbito comunitário e hospitalar, além das ações cuidativas de enfermagem. Na comunidade, utilizaram-se as modalidades de grupo de mulheres-gestantes e visita destas mulheres à maternidade, no último trimestre gestacional. No hospital, foi realizada a assistência de enfermagem durante o processo parir/nascer, enfatizando o protagonismo das mulheres neste momento. Conclui-se serem necessárias(os): a ampliação do debate sobre a proposição da humanização, superando resistências quanto a sua implantação; maior visibilidade do papel do enfermeiro nesse processo; arranjos intersetoriais na formação e atuação profissional, pois repercutem na atenção às usuárias; fomento à reflexão crítica de docentes, discentes, profissionais e das mulheres sobre a urgente modificação das práticas e saberes à atenção no processo parir/nascer, ainda, vigentes no país.

Descritores: Enfermagem; Saúde da mulher; Parto humanizado; Educação em saúde.

ABSTRACT: In this article, we report the experiences next to the pregnant-womanmother in practice care provided in a family health strategy and a maternity hospital. The actions included: educational practices in hospital and community spheres. In this, we used the method of group-pregnant women and visiting the maternity in the last trimester. That assistance of nursing during the birth process, emphasizing their lead role. It is necessary to be more visible role for nurses in this process; the broadening of the debate on the rhetoric of humanization; overcoming resistances about its implementation; which requires intersectional arrangements in formation and professional acting; promotion of a critic-reflexive positioning of teachers, students, professionals and users regarding the urgent change of practices and current knowledge to the attention, still prevailing in the country, child delivery.

Descriptors: Nursing; Women's health; Humanizing delivery; Health education.

\footnotetext{
${ }^{1}$ Enfermeira. Especialista em Unidade de Terapia Intensiva. Professora do Curso Técnico em Enfermagem do Sistema Galileu de Ensino/Santiago. Enfermeira do Hospital de Caridade Astrogildo de Azevedo/Jaguari. Santiago, RS, Brasil. E-mail: elzavelasque.enf@gmail.com.

${ }^{2}$ Enfermeira. Mestre em Enfermagem. Enfermeira do Pronto Socorro Pediátrico do Hospital Universitário de Santa Maria da UFSM. Professora da Universidade Regional Integrada do Alto Uruguai e das Missões/Campus Santiago. Santa Maria, RS, Brasil. E-mail: vmprade@yahoo.com.br.

${ }^{3}$ Enfermeira. Mestre em Enfermagem. Professora Assistente do Centro de Educação Superior do Norte do Rio Grande do Sul da Universidade Federal de Santa Maria (CESNORS/UFSM). Pesquisadora do Núcleo de Estudos e Pesquisas sobre Mulher, Gênero e Políticas Públicas da Universidade Federal de Santa Maria. Santa Maria, RS, Brasil. E-mail: fb.cabral@terra.com.br.
} 


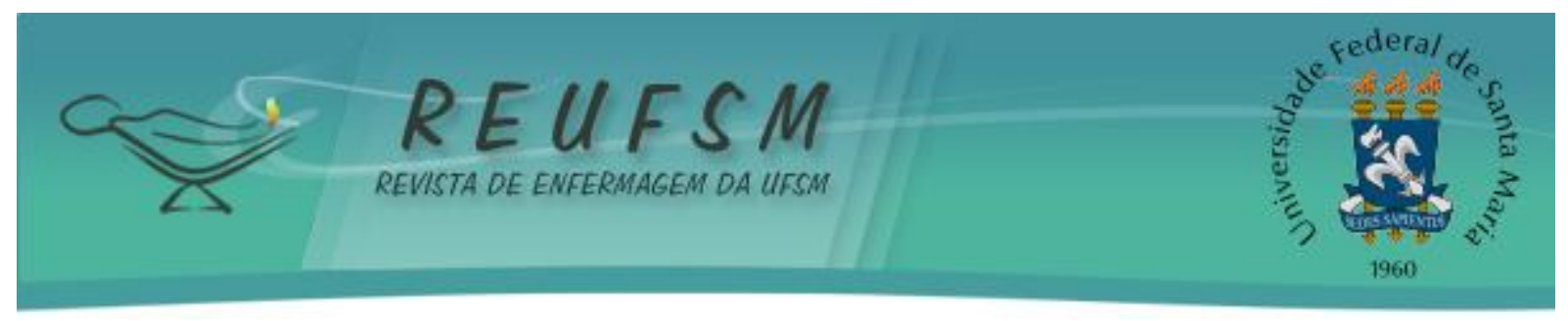

RESUMEN: Este artículo relata vivencias junto a la mujer-embarazada-parturienta en la práctica asistencial desarrollada en una estrategia de salud de la familia y en la maternidad de un hospital. Las acciones comprendieron: prácticas educativas en los ámbitos hospitalario y comunitario. En la comunidad, se utilizaron las modalidades de grupo de mujeres-embarazadas y su visita a la maternidad en el último trimestre de gestación. En el hospital, la asistencia de enfermería en el proceso parir/nacer; enfatizando el protagonismo de la mujer. Se consideró necesario una mayor visibilidad del rol del enfermero en este proceso; la ampliación del debate sobre la retórica de la humanización, superando resistencias en lo tocante a su implementación; ajustes intersectoriales en la formación y actuación profesional; fomento al posicionamiento crítico-reflexivo de docentes, discentes, profesionales y usuarias sobre la urgente modificación de las prácticas y saberes a la atención en el proceso de parir/nacer, aún vigentes en el país.

Descriptores: Enfermería; Salud de la mujer; Parto humanizado; Educación en salud.

\section{INTRODUÇÃO}

0 parto é um evento singular. Assim, o respeito e valorização das vivências de cada mulher-mãe são fundamentais à humanização do processo parir/nascer - período que compreende o início do trabalho de parto, parto e nascimento - ganhando centralidade o entendimento de que os modos como os sujeitos elegem determinadas opções de viver, organizam suas escolhas e criam possibilidades para satisfazer suas necessidades, desejos e interesses é um processo que se dá no contexto da própria vida ${ }^{1-3}$, consubstanciado pelos princípios que sustentam o processo gestar, parir/nascer com responsabilidade.

Estes princípios coadunam-se com a perspectiva da humanização que traz em seus pressupostos a valorização dos sujeitos inseridos no processo de produção da saúde ${ }^{4}$, como da qualidade técnica e ética do cuidado, mediante a adoção de posturas acolhedoras dos profissionais de saúde e da interação com as mulheres-gestantes-parturientes e suas famílias, no reconhecimento dos direitos do usuário, de sua subjetividade e referências culturais $^{5}$, contrapondo-se à lógica de sujeição que, geralmente, as mulheres são submetidas pelo processo de naturalização de uma identidade construída e valorizada social e culturalmente enquanto "grávidas" e "mães". ${ }^{1}$

Estas recomendações estão alicerçadas nos documentos oficiais da Organização Mundial da Saúde (OMS); Ministério da Saúde (MS) e da Rede Nacional pela Humanização do Parto e Nascimento (REHUNA), quanto à adoção de medidas e procedimentos sabiamente benéficos na atenção ao parto, evitando-se práticas intervencionistas e desnecessárias que, embora tradicionalmente realizadas, não beneficiam a mulher, nem o recém-nascido, acarretando freqüentemente maiores riscos para ambos. ${ }^{6}$

Nesse enfoque, os aspectos relativos ao movimento pela humanização do parto ${ }^{7-9}$ convergem para o compromisso dos profissionais ${ }^{10-12}$ que atuam no campo da saúde das mulheres, promovendo autonomia e cidadania para que participem mais criticamente da atenção a sua saúde.

A consecução dessas medidas requer atitudes éticas e solidárias destes profissionais, bem como produção de vínculo, apoio, confiança e tranqüilidade, atenção acolhedora com privacidade, mais autonomia, privilegiando condutas que rompam com a infantilização e despersonalização, muitas vezes, impostas às mulheres, especialmente, no processo parir/nascer. ${ }^{4,6-8}$

Ainda, quanto às possibilidades e desafios emergentes com a proposição da humanização do parto, destaca-se neste processo, a necessidade da ampliação e 


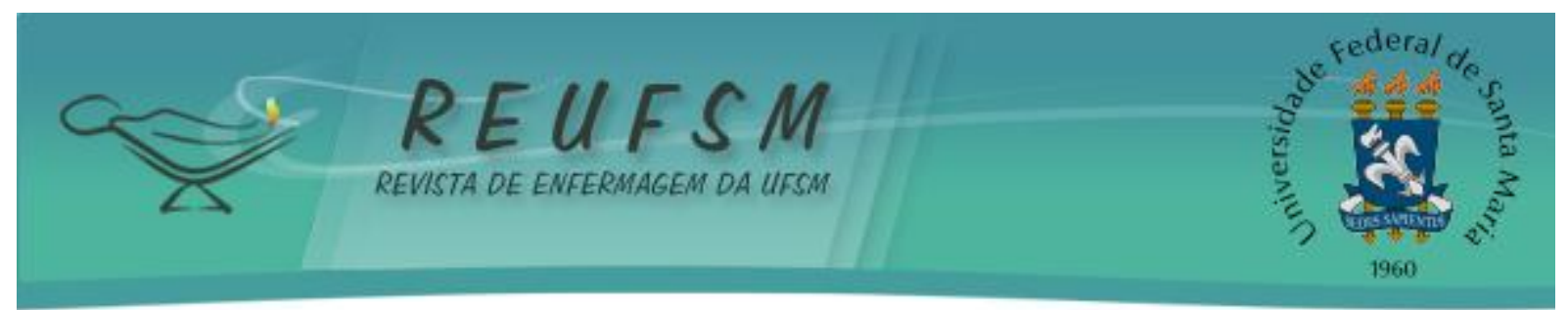

visibilidade do papel do enfermeiro, para que mudanças mais contundentes ocorram à implantação e êxito dessas propostas, as quais requerem investimentos no âmbito da formação e atuação destes profissionais.

Nelas, também se inclui o compromisso do enfermeiro de agregar ao componente assistencial do cuidado, intervenções educativas e humanizadoras às mulheres no ciclo gravídico-puerperal, visando um parto saudável, as quais precisam iniciar no pré-natal, estendendo-se na internação hospitalar, devido ao caráter processual emblemático das vivências femininas nesta fase, provenientes do contexto sócio-cultural.

Para desconstruir mitos correntes no imaginário sócio-cultural de muitas mulheres-grávidas e de seus familiares, quanto às ações da equipe de saúde de um centroobstétrico, durante o trabalho de parto e parto, como: "morrer de dor", "tirar o bebê a ferros", colocar o bebê "embaixo de uma torneira d'água fria", imediatamente ao seu nascimento e, também, para qualificar a assistência de enfermagem a essas mulheres, desenvolveu-se esta prática assistencial, a qual se constituiu no Trabalho de Conclusão de Curso (TCC). Assim, o objetivo deste artigo é relatar vivências da prática assistencial desenvolvida junto às mulheres-gestantes-parturientes, em um município do interior do Rio Grande do Sul.

\section{A PRÁTICA ASSISTENCIAL: PERCURSO E AÇÕES}

As ações educativas e de cuidado às mulheres-gestantes-parturientes foram realizadas por um concluinte do Curso de Graduação em Enfermagem, em 2008, nos âmbito comunitário e hospitalar. Tornaram-se sujeitos desta prática assistencial: mulheres-gestantes-parturientes e a equipe de enfermagem do centro- obstétrico, sendo que todos expressaram sua concordância, quanto a essas ações, mediante a assinatura do Termo de Consentimento Livre Esclarecido, conforme preconizado pela resolução 196/96. ${ }^{13}$

Como estratégia metodológica, desenvolveram-se as ações da prática assistencial no centro-obstétrico e, ainda, teve uma participação no grupo de mulheres-gestantes, já existente em uma Estratégia Saúde da Família (ESF), para abordar temáticas relativas ao trabalho de parto e parto. Cabe esclarecer que, nesta ESF, havia outro graduando e que, por vezes, as atuações de ambos complementaram-se, mais especialmente nas ações educativas relativas ao processo parir/nascer.

Nessa ESF, durante os encontros semanais, que totalizaram oito, os temas abordados nas práticas educativas seguiram uma agenda flexível às necessidades das usuárias, tais como: preparação para o parto, amamentação, autocuidado, depressão puerperal e cuidados com o bebê.

Todos os temas foram pautados na abordagem problematizadora, ou seja, as reflexões ocorreram a partir das interrogações e necessidades manifestadas pelas mulheres-gestantes e se tomou a precaução, por exemplo, de utilizar um discurso de fácil compreensão, sem linguagem técnica em demasia, distante da transmissão centrada apenas em informações/orientações para a mudança de comportamentos individuais a partir de decisões informadas ${ }^{1}$, enfocando o direito à participação ativa das mulheres no processo parir/nascer.

Dessa participação no grupo de mulheres-gestantes emergiu a articulação da visita das mulheres-gestantes, que estavam no último trimestre gestacional, ao centroobstétrico, no qual realizariam seus partos.

Cabe esclarecer que os critérios para a visitação foram: participação efetiva no grupo de mulheres-gestantes da ESF; estar no último trimestre gestacional e manifestar o desejo de conhecer o local onde "dariam à luz". Para tanto, primeiramente, foi agendada a visita. Posteriormente, formaram-se os subgrupos de até cinco mulheres, os quais foram 


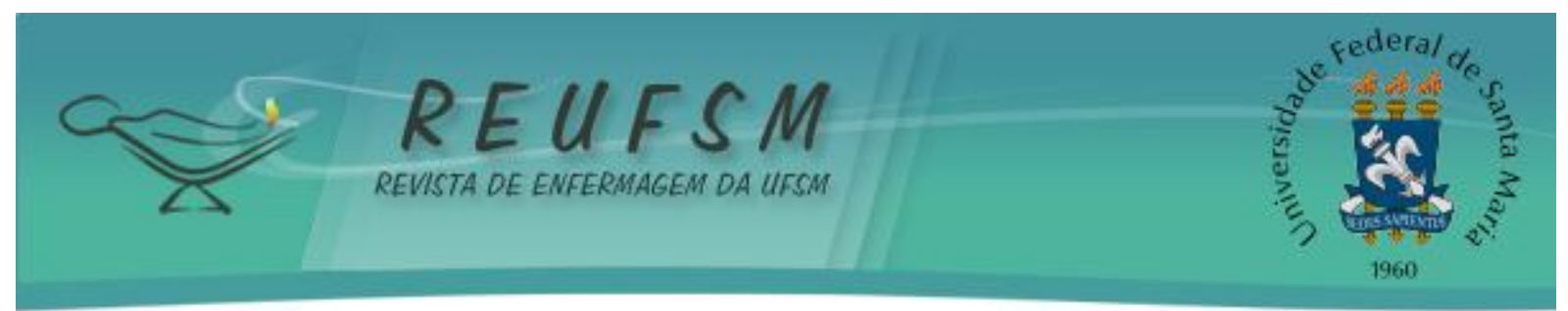

acompanhados pelos enfermeiros e pelos dois graduandos da ESF e do centro-obstétrico, respectivamente.

Dada a subjetividade que perpassam as relações de cuidado entre profissionais de saúde e usuárias, o acolhimento adquire expressão significativa, pois se configura a partir do encontro e valorização de demandas articuladas à produção de relações de escutas e responsabilizações, da constituição de vínculos e de intervenções que mobilizam recursos individuais e coletivos direcionados à promoção de modos de viver saudável, enquanto projetos de felicidade. ${ }^{14}$

Nessa concepção, e também pelo reconhecimento do acolhimento e vínculo como importantes dispositivos de humanização no processo parir/nascer, esses aspectos foram iniciados no atendimento pré-natal, durante a participação no grupo de mulheresgestantes e foi estendido para o âmbito hospitalar, mediante a ambientação dessas mulheres com o centro-obstétrico.

Uma ação inovadora, neste TCC, foi a visita de nove mulheres-gestantes ao centro-obstétrico, que visou a diminuição da ansiedade por meio da ambientalização com o local onde fariam seus partos, ratificando o cuidado de enfermagem humanizado.

No desenvolvimento da prática assistencial, do grupo de mulheres-gestantes que visitou o centro-obstétrico, três foram assistidas pelo graduando durante toda a permanência no serviço, ou seja, acolhimento da mulher-parturiente, acompanhamento do seu trabalho de parto e parto, bem como de sua acomodação e do bebê no alojamento conjunto, após receber a alta do centro-obstétrico.

Nessas vivências, observou-se que essas mulheres chegavam à maternidade demonstrando posturas mais confiantes e seguras quanto aos procedimentos obstétricos a que seriam submetidas, além de manifestarem ciência de seus direitos, apesar do desconforto inerente ao processo parir/nascer.

Quanto às outras seis mulheres que também participaram da visitação e que foram atendidas somente pela equipe de saúde do centro-obstétrico, ou seja, sem a presença do acadêmico, os relatos sobre a postura daquelas mulheres durante o processo de parir/nascer coincidem com os supramencionados.

Outro aspecto a ser referido é que todas participantes do grupo de mulhesgestantes da ESF, que visitaram previamente o centro-obstétrico, mantiveram posturas pró-ativas durante 0 processo parir/nascer em relação àquelas que não tiveram essa vivência.

No que tange às ações desenvolvidas especificamente no centro-obstétrico, as mulheres-parturientes foram acolhidas desde o momento da internação, sendo que, nos cuidados obstétricos prestados, o graduando explicava todos os procedimentos e suas finalidades, enfatizando a importância de uma participação mais ativa no processo parir/nascer.

Outra ação implementada e que teve por objetivo minimizar a ansiedade e a dor no trabalho de parto foi a adoção de métodos não farmacológicos/ psicoprofiláticos de alívio à dor no trabalho de parto, que compreendeu medidas de conforto e apoio às mulheres-parturientes, tais como: massagens relaxantes, banhos mornos, exercícios com bola de Pilates, incentivo à manutenção de posições verticais, ou seja, a deambulação e permanência na posição de cócoras, por períodos suportáveis pelas mulheres-parturientes.

Ainda, no intuito de auxiliar as mulheres neste processo foi confeccionada uma cadeira com o fim de promover o relaxamento do períneo durante o trabalho de parto. ${ }^{15}$ Ressalta-se que a implementação das ações ${ }^{15}$ desta prática assistencial tem sido enfatizadas/evidenciadas/corroboradas/reiteradas por autores ${ }^{6-10,12,16}$ como importantes estratégias para a humanização da atenção ao parto. 


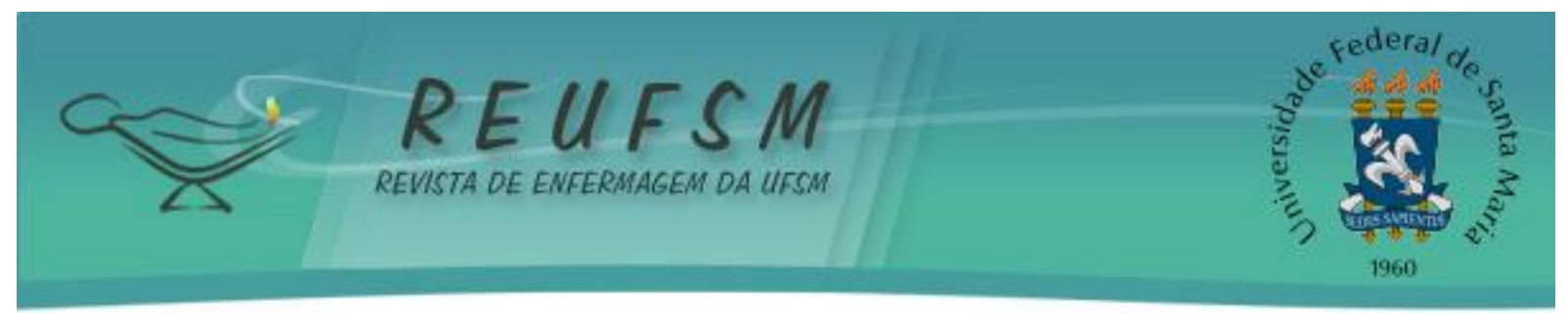

Nessa lógica de ação, o parto normal foi incentivado, pois se tomou por referência seus benefícios à saúde das mulheres, uma vez que com o passar do tempo, o incremento de tecnologias e de técnicas obstétricas, este tipo de parto tem sido preterido pela emblemática cultura pró-cesárea, legitimada pela falácia da possibilidade do parto sem dor ${ }^{1 .}$

Também foi estimulado o início da amamentação, ainda na sala de parto ${ }^{10}$, favorecendo o vínculo mãe-filho, respeitando-se sempre, o desejo e as condições de saúde das mulheres-parturientes-puérperas e dos bebês.

Outra ação importante e que corroborou para a qualificação e humanização da atenção obstétrica compreendeu o incentivo à participação do pai e/ou acompanhante de escolha das mulheres-parturientes ${ }^{10}$ durante 0 processo parir/nascer, direito constituído, mas pouco respeitado pelos profissionais de saúde e instituições, em sua maioria.

Cabe mencionar que, várias vezes, esta atitude do graduando causou estranheza e desconforto na equipe de saúde do centro-obstétrico daquele hospital, embora esses profissionais fossem sabedores e/ou conhecedores da Lei Federal $n^{\circ} 11.108$, de 07 de abril de $2005^{17}$, que ampara as mulheres nesta prerrogativa que lhes garante o direito de escolher seu acompanhante durante o trabalho de parto, parto e pós-parto imediato, no âmbito do Sistema Único de Saúde (SUS).

O embate decorrente da presença desses novos sujeitos no cenário do parto ${ }^{10-11,16-}$ ${ }^{17}$ produz reações conflitantes nos profissionais, pois enquanto alguns são mais sensíveis e receptivos às mudanças, outros, sentem-se invadidos, ameaçados e questionados sobre suas condutas profissionais.

Nessas circunstâncias, outra vez, evidencia-se o papel do enfermeiro na proposição de práticas de cuidado humanizado ao parto, favorecendo o protagonismo feminino no exercício da autonomia, da cidadania e do respeito aos direitos reprodutivos para que, de fato, suas escolhas e desejos sejam valorados, resgatando o direito das mulheres-parturientes serem donas de seus corpos e sujeitos do nascimento de seus filhos, ressignificando estas vivências. ${ }^{1}$

Ainda, durante os cuidados de enfermagem, o processo educativo foi retomado, reforçando-se orientações e esclarecendo dúvidas surgidas com as demandas da maternidade no puerpério, que é entendido como o período de maior vulnerabilidade, dada a complexidade dessa experiência, a qual é conferida pelo entrelaçamento de aspectos biológicos, psicológicos, emocionais, comportamentais, relacionais, sócio-culturais, econômicos e por questões de gênero. ${ }^{1}$ Estas compreendidas como ferramenta teórica e política de caráter relacional, para o qual as análises e intervenções empreendidas, neste campo de estudos, devem tomar como referência as relações - de poder - e as muitas formas sociais e culturais que, de forma interdependente e interrelacionada, educam homens e mulheres como "sujeitos de gênero". ${ }^{18}$

Durante a internação hospitalar, as mulheres permaneceram junto a seus filhos ${ }^{10}$, em sistema de alojamento conjunto, que tem por finalidade favorecer o vínculo mãe-filho, o estabelecimento precoce e o apoio à amamentação, o exercício do autocuidado e do cuidado com o bebê, visando à alta hospitalar.

Destaca-se ainda que, como para algumas mulheres, a adaptação ao papel materno no puerpério requer tempo maior, a adoção da perspectiva da humanização implica, além da consideração da interrelação dos aspectos físicos, emocionais e relacionais implicados neste processo, uma atitude profissional de respeito e valoração à singularidade de cada mulher-mãe. ${ }^{15}$ 


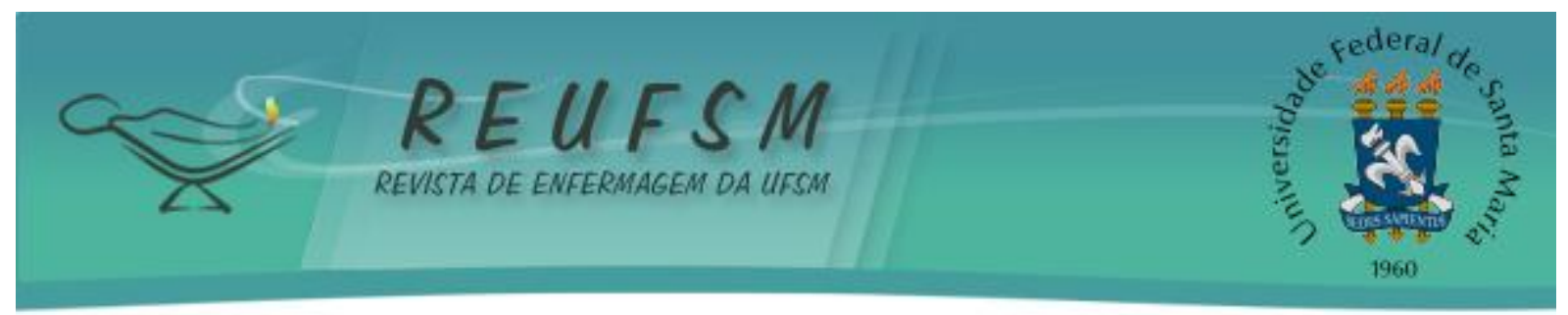

\section{CONSIDERAÇÕES FINAIS}

As vivências desta prática assistencial demarcam a potencialidade do enfermeiro e concorrem para que a humanização do processo parir/nascer ultrapasse o campo do direito, quebrando resistências dos profissionais de saúde para sua efetiva implantação nos serviços de saúde e, mais especialmente, no âmbito do Sistema Único de Saúde.

A relevância da presença do pai e/ou acompanhante de escolha da mulher foi evidenciada nas ações educativas e de cuidado de enfermagem. Entretanto, apesar de direito assegurado pela Lei Federal $n^{\circ} 11.108$, nesta instituição, ainda não é permitida a participação destes no processo parir/nascer, exceto, nos horários de visitas ou, excepcionalmente, quando autorizado pelos médicos obstétras.

Como diferencial desta prática, destaca-se a visita das participantes do grupo de mulheres-gestantes ao centro-obstétrico, previamente ao processo de parir/nascer. Esta estratégia inovadora na região, foi apontada pelas mulheres assistidas como positiva à minimização da ansiedade e desmistificação do imaginário sócio-cultural que caracteriza o parto como um evento extremamente doloroso, perigoso e desconhecido.

Devido aos paradoxos que emergiram com o movimento pela humanização do parto $^{7-9}$, acredita-se que o enfrentamento dessa problemática requer mudanças mais profundas, que ultrapassem os ordenamentos técnicos e legais, as quais não serão possíveis sem arranjos intersetoriais.

As considerações aqui apresentadas sinalizam para a responsabilidade e o papel do enfermeiro na promoção da saúde das mulheres no ciclo gravídico-puerperal, na educação em saúde e na assistência ao processo parir/nascer como uma necessidade, dentre outras, que se fazem imprescindíveis do ponto de vista macroestrutural, que requerem investimentos e mudanças na formação de profissionais para a saúde, visando à superação da cultura biomédica que sustenta o processo de medicalização do parto.

Também, contribui à ampliação e ao refinamento do debate já em curso sobre a humanização do parto, instigando o posicionamento critíco-reflexivo de docentes, discentes, profissionais e usuárias dos serviços de saúde do Sistema Único de Saúde sobre a urgente modificação das práticas e saberes que modulam a atenção ao parto, ainda, vigentes no país.

Sintetizando, com o desenvolvimento desta prática assistencial, como Trabalho de Conclusão de Curso, foi possível uma aproximação dos desejos/interesses/querer das mulheres-gestantes-parturientes, quantos aos aspectos dos seus processos parir/nascer e evidenciou serem necessárias(os): a ampliação do debate sobre a proposição da humanização do parto, superando resistências quanto a sua implantação; maior visibilidade do papel do enfermeiro nesse processo; arranjos intersetoriais na formação e atuação profissional, pois repercutem na atenção às usuárias; fomento à reflexão crítica de docentes, discentes, profissionais e das mulheres-gestantes-parturientes sobre as práticas e saberes à atenção no processo parir/nascer, enfatizando o protagonismo das mulheres no nascimento de seus filhos.

\section{REFERÊNCIAS}

1. Cabral FB. Vulnerabilidade de puérperas: olhares de equipes do programa saúde da família em Santa Maria/RS [dissertação]. Porto Alegre : Universidade Federal do Rio Grande do Sul. Escola de Enfermagem; 2007. 


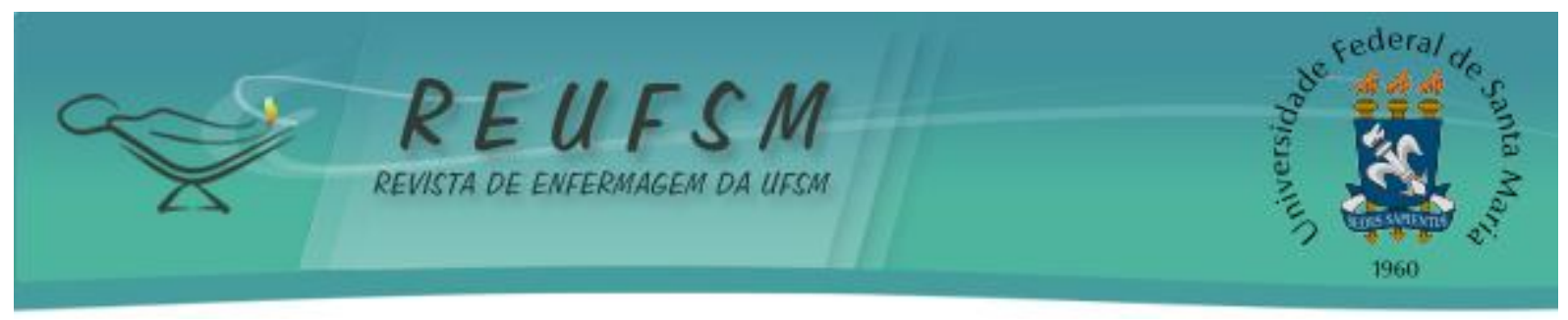

2. Czeresnia D. O conceito de saúde e a diferença ente prevenção e promoção. In: Czeresnia D, Freitas CM, organizadores. Promoção da saúde: conceitos, reflexões, tendências. Rio de Janeiro: Fiocruz; 2003. p.39-53.

3. Oliveira DLLC de. A nova saúde pública e a promoção da saúde via educação: entre a tradição e a inovação. Rev Lat-Am Enferm. 2005;13(3):423-31.

4. Ministério da Saúde (BR). Manual técnico: pré-natal e puerpério - atenção qualificada e humanizada. Série A, Série Direitos Sexuais e Reprodutivos - Caderno no 5 . $3^{a}$ ed. Brasília (DF); 2006.

5. Deslandes SF. Análise do discurso oficial sobre humanização da assistência. Cienc Saúde Colet. 2004;S(1):12-16.

6. Ministério da Saúde (BR). Programa de humanização no parto e puerpério. Brasília: Secretaria de Políticas de Saúde - SPS/Ministério da Saúde, 2000.

7. Diniz CSG. Humanização da assistência ao parto no Brasil: os muitos sentidos de um movimento. Cienc Saúde Colet. 2005;10(3):627-637.

8. Tornquist CS. Paradoxos da humanização em uma maternidade no Brasil. Cad Saúde Publica. 2003;19(S.2):419-427.

9. Tornquist CS. Armadilhas da nova era: natureza e maternidade no ideário da humanização do parto. Rev Estudos Feministas. 2002;10(2):483-92.

10. Nagahama EAI, Nagahama, SM. Práticas de atenção ao parto e os desafios para humanização do cuidado em dois hospitais vinculados ao Sistema Único de Saúde em município da Região Sul do Brasil. Cad Saúde Pública. 2008; 24(8):1859-68.

11. Carvalho MLM. Participação dos pais no nascimento em maternidade pública: dificuldades institucionais e motivações dos casais. Cad Saúde Pública. 2003; 19:38998.

12. Brüggemann OM, Osis MJD, Parpinelli MA. Apoio ao nascimento: percepções de profissionais e acompanhantes escolhidos pela mulher. Rev Saúde Pública. 2007; 41:4452.

13. Ministério da Saúde (BR). Resolução n. 196/CN, de 10 de outubro de 1996. Diretrizes e norma regulamentadora de pesquisa em seres humanos. Resolução. Diário Oficial da União, Brasília, 1996.

14. Ayres JRCM. Organização das ações de atenção à saúde: modelos e práticas. Saúde e Sociedade. 2009;18(S.2):11-23.

15. Velasque EAG. A Participação do Enfermeiro no processo de parir/nascer: uma estratégia de cuidado de enfermagem na perspectiva da humanização do parto [monografia de conclusão de curso]. Santiago (RS): Universidade Regional Integrada do Alto Uruguai e das Missões/Campus Santiago; 2008.

16. Tomeleri KR, Pieri FM, Violin MR, Serafim D, Marcon SS. "Eu vi meu filho nascer": vivência dos pais na sala de parto. Rev Gaúcha de Enferm. 2007;28(4): 497-504.

17. Presidência da República (BR). Lei $n^{\circ}$. 11.108, de 07 de abril de 2005: altera a Lei $n^{\circ}$. 8.080 , de 19 de setembro de 1990, para garantir as parturientes o direito à presença de acompanhante durante o trabalho de parto, parto e pós-parto imediato, no âmbito do Sistema Único de Saúde - SUS [página na Internet]. Brasília (DF); 2005 [acesso em 2007 jan 


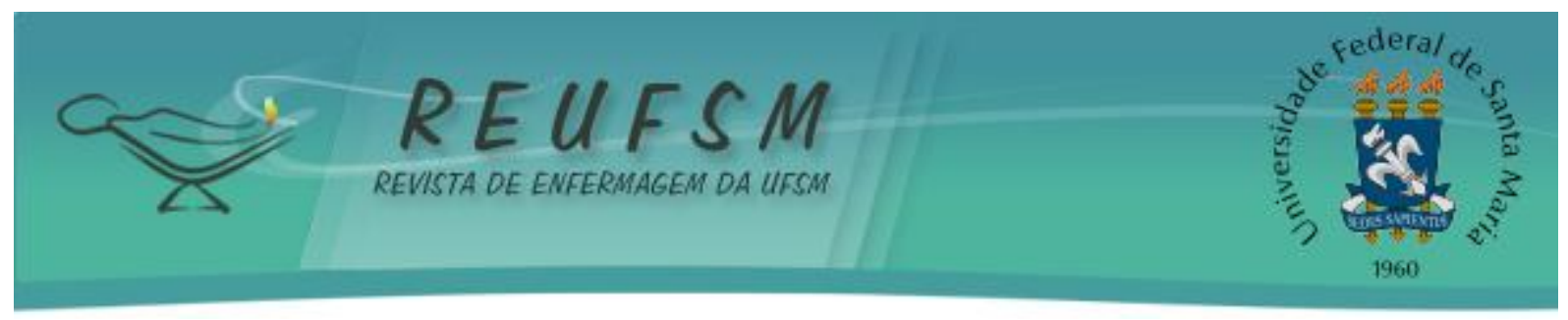

11]. Disponível em: http://www.planalto.gov.br/ccivil_03/_Ato20042006/2005/Lei/L11108.htm.

18. Meyer DE. Teorias e políticas de gênero: fragmentos históricos e desafios atuais. Rev Brasileira de Enferm. 2004; 57(1):13-8.

Data de recebimento: 03/09/2010

Data de aceite: 09/11/2010

Contato com autora responsável: Elza Aparecida Gomes Velasque

E-mail: elzavelasque.enf@gmail.com. 